INTERVIEW

\title{
Paula Moynihan: 'We really need to look at a holistic, systemic approach'
}

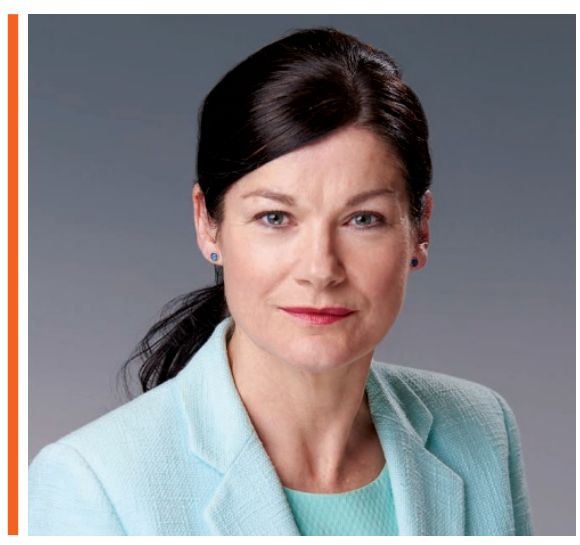

You've recently been elected to the IADR, so what are your plans?

I've just started a four-year term so I'm vice president this year, then president elect, and then I'll be president in the centenary year, the meeting for which will be held in Washington DC in 2020 so I'm really excited about that, it's very much an honour. For the presidency I'd like to help bridge the gap between oral health and systemic health. I think this is increasingly important if we're looking at global health and the UN Sustainable Development Goals and I think I'm quite well placed to see where oral health might contribute to achieving some of those. You also contribute to the ongoing plans of the Association so I hope that I can steer it in what I think is the right direction for members.

\section{Is oral health and systemic health} already on the agenda with the IADR or is it something that you feel needs to be brought out more?

Well of course the mouth is part of the body and I don't think we should be trying to manage and treat it in isolation. An example of course, very close to my own heart, would be sugars and its association with, not only dental caries, but also obesity, so efforts to reduce sugars are relevant to many more professions than just the dental profession. Another example might be the bidirectional link

Jonathan Lewney, Associate Editor for the BDJ Portfolio, interviews Professor Paula Moynihan. Paula is Professor of Nutrition \& Oral Health at Newcastle University School of Dental Sciences, Director of Newcastle University Centre for Oral Health Research, and Director of the World Health Organisation Collaborating Centre for Nutrition and Oral Health. In December 2016, Paula was elected Vice-President of the International Association of Dental Research (IADR), which means she will become IADR President in 2019.

between diabetes and periodontal disease. At the moment diabetes is a huge issue, especially in the lower and middle income countries that are beginning to consume a westernised diet, so there's real links there with efforts to control and manage periodontal disease. If you look at the UN Sustainable Development Goals relating to having clean water for all, well actually maybe we should be pushing for clean, appropriately fluoridated water for all. The IADR for a long time has been building relationships with the World Health Organisation (WHO) and the FDI, and to build that link between IADR and WHO we really need to look at a holistic, systemic approach.

\section{How did you first get involved with the WHO?}

Most of the credit for that goes to Andrew Rugg-Gunn, who is Emeritus Professor of Child Dental Health at Newcastle University. Andrew worked very hard to establish the WHO Collaborating Centre for Nutrition and Oral Health here. He made me deputy director, mentored me through many initial WHO meetings, and then when he eventually retired I stepped into those big shoes and took over as director of the centre. We're now in our fifth term as a WHO Collaborating Centre for Nutrition and Oral Health and celebrating 21 years as a collaborating centre this August.
I'm currently looking at starch and oral health as part of a team for the WHO, as you know because you're a member of the team! I'm about to embark on another systematic review for the WHO looking at the aetiological factors for early childhood caries.

\section{When I started work with you on} that systematic review on starch and oral health I learnt things from you I hadn't come across before in my own research. Are people often surprised to hear that you're not a dentist by background?

Oh yes! I worked with someone years ago at the WHO and she realised after some time and she said 'What do you mean, you're not a dentist?!... I felt like a total fraud! But that said, although my educational background is nutrition, my research background is nutrition and dentistry and I've worked in that now for over 25 years, so my research is both subjects. You could say that although I'm not a clinical dentist I'm a clinical dietitian and I've been working in dentistry since I took up the position here in 1991; that's a long time!

You worked on oral health and nutrition for older people and it does seem to be getting more attention but do you think we're getting anywhere close to doing enough in this area? 
Not yet, no! Research that's been conducted here [at Newcastle] led by Becky Wassel has been looking at care pathways for oral health in care homes. No-one really knows what is an appropriate level of care so I think we need more research into that area and we also need better awareness and training of those carers working in care homes. Many years ago nearly all residents would have had dentures but we're now in the situation where $70 \%$ of people entering a care home will have some of their own teeth and will have cherished and looked after them all their life only to then be exposed to a cariogenic diet and a lack of oral healthcare. Then add the medications and the dry mouth and the lack of oral hygiene and it can lead to very, very rapid deterioration of oral health and in particular root caries.

\section{Do you think we'll ever solve the issue of tooth decay?}

Well, it's a totally preventable disease, but to get rid of the cause, which is dietary sugars, it's not just about giving patients advice. We really need both upstream and downstream approaches: making sure that there are less sugars out there, that we're exposed to less of it, and that less of it is produced - so let's see if we can successfully reduce sugars intake to help prevent dental caries but also to help address the obesity problem. Fluoride and oral hygiene are important but I think there's only so much we can achieve with fluoride. Dental caries isn't a fluoride deficiency disease, the fluoride is simply mopping up some of the damage caused by sugars, or some might argue that it's simply delaying it and making cavitation occur at a later stage, that fluoride makes the teeth more resistant but eventually the decay still occurs, as highlighted in the work of late Aubrey Sheiham and Eduardo Bernabie at UCL. It's not universally accepted but I still think you need to get rid of the cause. Aubrey worked with Eduardo Bernabie and suggested that dental caries increases with age independent of cohort effects so that would suggest now that dental caries is occurring later, so we need to get rid of the cause, and the cause is dietary sugars.

\section{Which research that you've carried out has had the biggest impact and why?}

Undoubtedly that's the systematic review, commissioned by the WHO, on amounts of sugars and dental caries which I did with Sarah Kelly. We found that we were still getting disease with sugars at $10 \%$ of total energy (the WHO threshold at the time) so we looked lower and found, albeit low quality evidence, to show that lower was better. For the first time the research showed all the data on sugars, focussing on amount, in one collective way. The paper's been cited over 200 times so that's great - people are reading it! And when you're talking about impact, well, impacting on global policy is a pretty big impact but also what's important is the knock-on effect that that will have as the WHO will set the precedent for other national bodies to either set policy, to bring in taxation, to look more deeply at health policies and school policies around sugars. It creates that drive for change and I think that's what's important. Since the sugars review has come out quite a few countries have introduced a tax on beverages sweetened with sugars, such as South Africa and England from next year. That might not be the only answer but it certainly sends out a consumer message that sugars are not good for you. We're also seeing food manufacturers lowering the sugars contents of their food. We heard the Kit Kat story not so long ago, so there is that move towards doing something about sugars. I was something else. Whole sectors of populations in these countries depend on sugar. I recently visited Southern India and came across wagons and wagons of sugar cane and the poorest looking farmers - that was their work - and then I'm saying 'reduce sugars'. It needs time, it needs planning. It's not just about health policy; it's about agricultural policy, educational policy, it's about food production.

And the term 'sugar', what should we be calling it in terms of the carious process? It depends who you're talking to! If you're talking to the public, 'added sugars' is a very good term. If we're working in an academic situation then I think the term 'free sugars', as used by the WHO, is the best term to use.

\section{Yes, because we still hear 'non-milk extrinsic sugars' and 'fermentable carbohydrates'...}

Well I definitely wouldn't use that term! To a nutritionist a 'fermentable carbohydrate' is a resistant starch that doesn't get digested in the GI tract but goes to the lower GI tract where

\section{'Dental caries isn't a fluoride deficiency disease, the fluoride is simply mopping up some of the damage caused by sugars, or some might argue that it's simply delaying it...'}

reading my muesli packet this morning and I picked up a brand I don't usually buy and I was horrified to see it was $27 \%$ sugars and on the side they declared that they added sugar to the grains when cooking it to make it taste better so I won't be buying that brand again... but they declared why they add sugar and I don't think you would have seen that on a packet a few years ago.

\section{If you had free rein to implement a single policy to reduce sugar consumption what would it be?}

Well, there isn't just one policy that would work. We need concerted efforts that go right from agricultural policy, the production of sugars, right down to the individual level. But if I was talking globally and looking at one policy, it would be agricultural. It would be for those high sugar-producing countries like India, Malaysia and Brazil, to change their agricultural policy so people can get their livelihood from all those friendly bacteria feed on it to produce acid because they ferment it. It's something that gets fermented in the large bowel so I don't think it's a helpful term and if we're working across professions we need to start using the same language and free sugars is simple for all professions to understand.

\section{At what point in your career in nutrition did you move into dentistry?}

Well, when I was doing my four-year undergraduate degree in nutrition someone was asking for volunteers to do a five-month research post at Newcastle University with a Dr Andrew Rugg-Gunn and I found myself putting my hand up. The reason I did was because I was at the end of my second year and I hadn't heard anything about oral health so I thought I might learn something! Little did I know that over 30 years later I'd still be sitting here today in the very office where I was in 1984 ! 
That's a great story! Now, something I'd really like to know - for someone who spends so much time researching sugar and nutrition, and we know we have to keep some things to a treat, what is your food treat? Do you like sugar?

I do sometimes have dark chocolate, with a cup of coffee. I tend not to have desserts - total opposite to when I was a child! I have much more of a savoury tooth, so my favourite food would have to be a really nice cheese ... preferably taken with a glass of wine!

Yes, because your tastes do change, don't they? And if you cut it out you want it less don't you?

I think that's the case. If I go to the US they put a lot of sugar in the salad dressings and I can't take it. I can't even eat their bread. That's the whole point about reformulation: manufacturers gradually decrease the levels so you don't notice but you come to accept that less sugary taste.

\section{What is your proudest moment?}

Well I don't see myself as a particularly proud person so that's a difficult one. Obviously
I was extremely proud to be elected by the members of IADR, that's overwhelming. But my first proud moment in my career was when I was awarded the Silver Medal by the Nutrition Society which is for 'excellence in research by a young scientist'. I got that when and the Prevention of Chronic Diseases. I had to present the oral health component at a meeting in Geneva with 40 delegates, including ministers of health, from all over the world. I gave my 20 minute presentation and then had two hours of questioning afterwards

\section{'There isn't just one policy that would work. We need concerted efforts that go right from agricultural policy, the production of sugars, right down to the individual level.'}

I was a lecturer back in 2004 and what was special for me was that it was a nutrition society giving me an award in excellence for work I'd done in oral health.

\section{What's the hardest thing you've ever done?}

From a work point of view when I had recently become involved with the WHO collaborating centre; I was part of the WHO Expert Consultation on Diet, Nutrition and quite often I say to myself 'well if I did that then, what am I worried about now?!'

Who do you admire most and why? Well this has to be my husband because I don't think many people would put up with me! He's my absolute rock. He's a great sounding board and he puts up with being home alone an awful lot when I'm off on my travels for IADR - so yes, it has to be my husband Matthew! 